\title{
Rare Use of National Languages in Europe for Communicating Scientific Information in Medicine
}

\author{
Izet MASIC ${ }^{\mathrm{a}, 1}$ and Slobodan M. JANKOVIC ${ }^{\mathrm{b}}$ \\ ${ }^{a}$ Academy of Medical Sciences of Bosnia and Herzegovina, Sarajevo, B\&H \\ ${ }^{\mathrm{b}}$ Department of Pharmacology, Faculty of Medical Sciences, Kragujevac, Serbia
}

\begin{abstract}
For many decades English language was dominant in international scientific communications, but during the last decade it threatens to become the only language for communicating medical science at international level. The aim of this article was to make an overview of publication practices in regard to language of publication of MEDLINE-referenced articles from European countries in year 2020. Scientific publications referenced in MEDLINE database during year 2020 were chosen for analysis. The inclusion criteria were publications affiliated with one of European countries, published in either English or national languages of those countries. The countries with less than 100.000 inhabitants were excluded from the study. Only 11 of 38 European countries had any number of medical publications in national language that were referenced in MEDLINE; the authors from twentyseven European countries completely stopped publishing in national language at international journals. While economic strenght of a country was strongly correlated with number of international publications per 100.000 inhabitants, the correlation with international papers published in national languages was much less pronounced. Researchers from majority of European countries are publishing their studies predominantly or only in international medical journals printed in English language. Additional efforts should be made in the future to promote publishing in national languages.
\end{abstract}

Keywords. International medical journals, national language, English language, Europe.

\section{Introduction}

For many decades English language was dominant in international scientific communications, but during the last decade it threatens to become the only language in medical science [1]. Many international and national journals changed their language from national to English in an attempt to improve bibliometric characteristics (number of citations and impact factor in the first place) [2]. Many, if not majority, from the scientific world believe that publishing in an international journal with impact factor is something that qualify one as a "scientist", and, since articles published in English language have much more chances to be cited [3], researchers who are non-native English language speakers should do their best to learn this language and publish their papers in English [4]. Several analyses showed that impact on wider community of

\footnotetext{
${ }^{1}$ Corresponding Author, Prof Izet Masic, PhD, FIAHSI, FACMI. E-mail: imasic@lol.ba
} 
scientific medical articles published in other languages except English is much less, because majority of researchers avoid even attempt to read an article published in other language [5]. However, it is important to have scientific communication in national language, because it enables deeper understanding of the topic by native readers and gives more chances for implementation of the results in practice, i.e. directly improves the healthcare quality [6]. The aim was to make an overview of publication practices in regard to language of publication of MEDLINE-referenced articles from European countries in year 2020 .

\section{Methods}

Scientific publications referenced in MEDLINE database [7] during year 2020 were chosen for analysis. The inclusion criteria were publications affiliated with one of European countries, published in either English or national languages of those countries. Also, only countries with more than 100.000 inhabitants were taken into account. The strategy used for search of the MEDLINE database included name(s) of each of European countries, with or without name of the respective language. The data about Gross Domestic Product (GDP) of European countries in 2020 and numbers of their inhabitants were taken from the web page of World Bank [8]. Number of publications in 2020 for each country was calculated per 100.000 inhabitants. Distribution of the data was tested for normality by Kolmogorov-Smirnov's test. Correlations between GDP per capita and number of publications per 100.000 inhabitants were tested for significance and extent by Spearman's rho coefficient. Probability of zero hypothesis was considered acceptable if less than 0.05. All calculations were conducted by SPSS, version 18 .

\section{Results}

In total 38 out of 44 European countries were included in the analysis. There was strong correlation between GDP per capita in 2020 and number of publications in 2020 referenced in MEDLINE and affiliated to respective country: Spearman's rho coefficient was $0.927, p=0.000$ (Figure 1). On the other hand, the correlation between GDP per capita in 2020 and number of publications in national language during 2020 referenced in MEDLINE and affiliated to respective country was much weaker, albeit statistically significant: Spearman's rho coefficient was $0.645, \mathrm{p}=0.000$ (Figure 2). Number of publications per 100.000 inhabitants referenced in MEDLINE and affiliated with certain European countries in 2020 and number of those published in national languages, yet referenced in MEDLINE are shown in the Figure 3. 


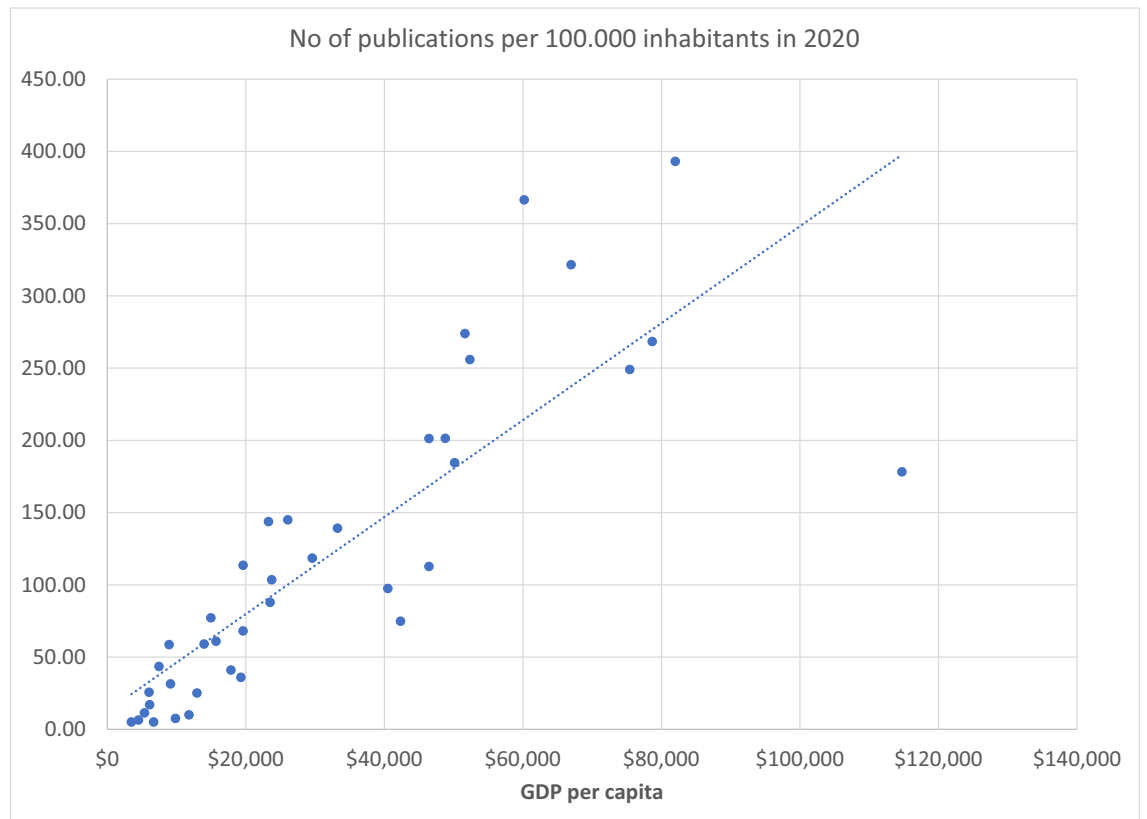

Figure 1. Correlation between GDP per capita in 2020 and number of publications per 100.000 inhabitants referenced in MEDLINE during 2020 and affiliated to certain European counrtries $(n=38)$.

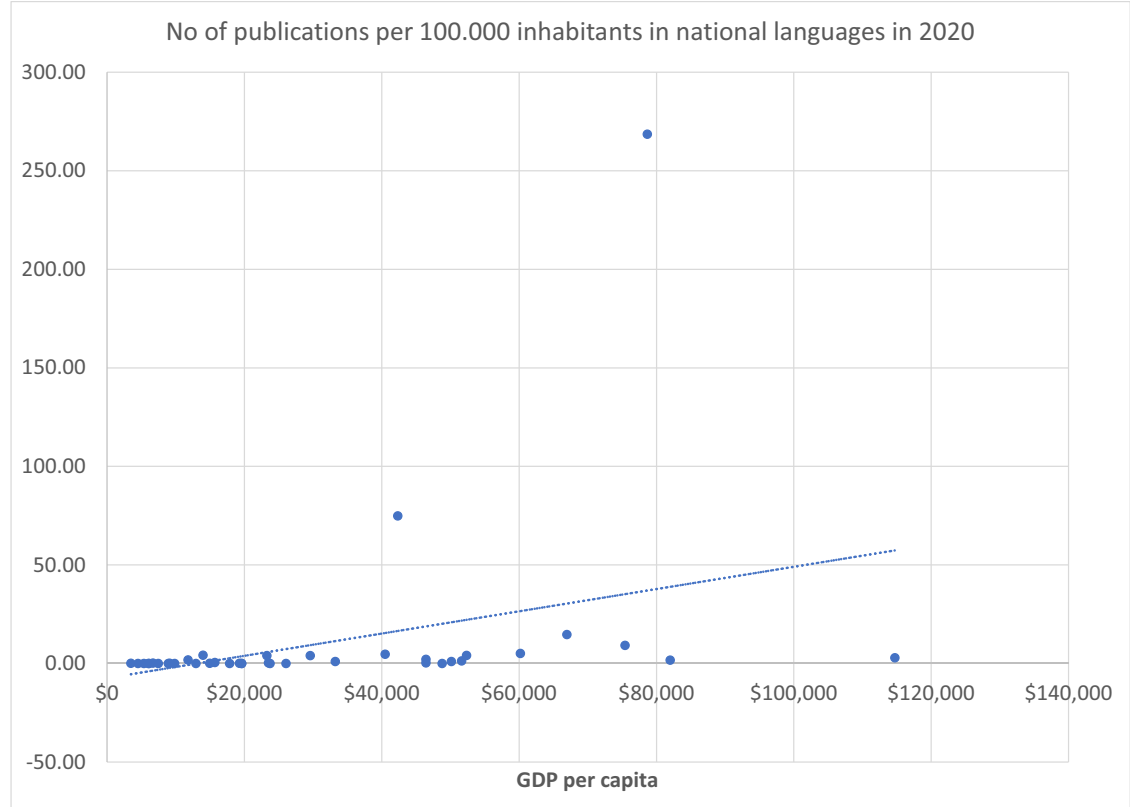

Figure 2. Correlation between GDP per capita in 2020 and number of publications in national languages per 100.000 inhabitants referenced in MEDLINE during 2020 and affiliated to certain European counrtries $(n=38)$. 


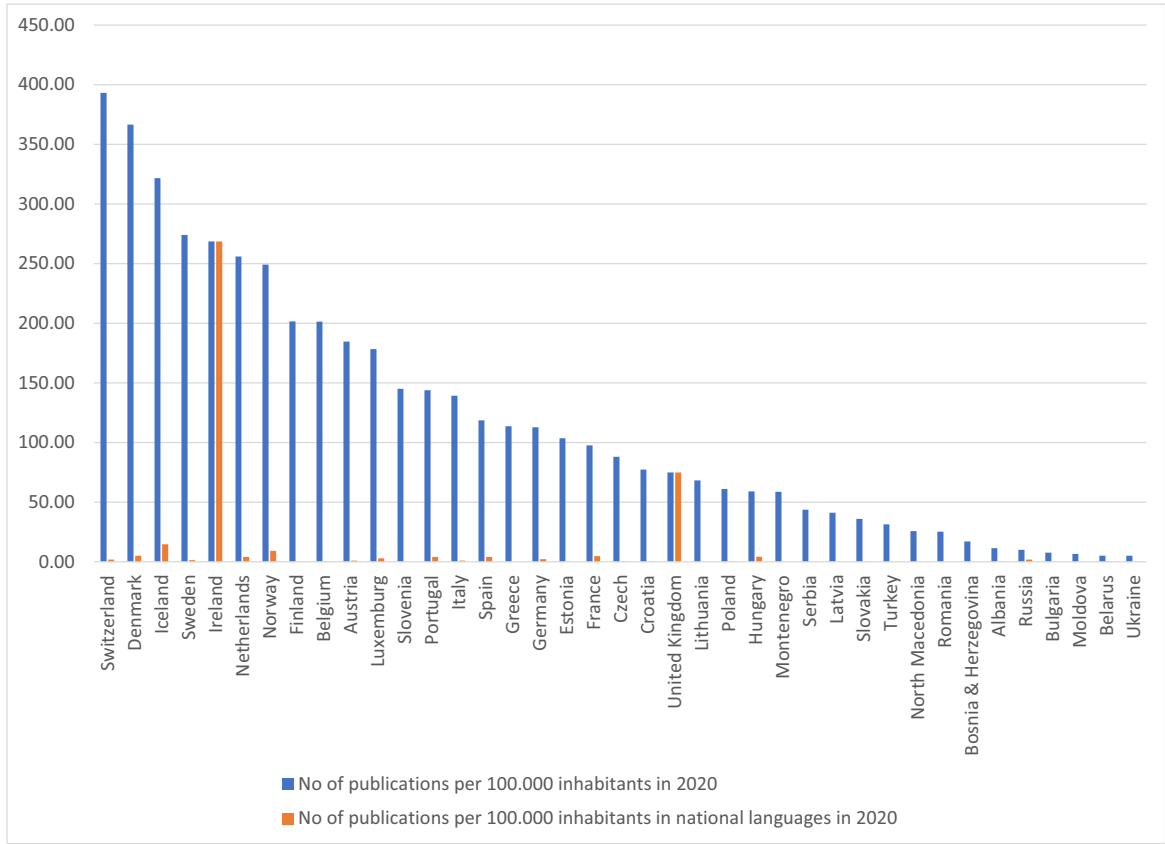

Figure 3. Number of publications per 100.000 inhabitants referenced in MEDLINE and affiliated with certain European countries in $2020(n=38)$.

\section{Discussion}

Our article showed that only 11 of 38 European countries had any number of medical publications in national language that were referenced in MEDLINE; the authors from twenty-seven European countries completely stopped publishing in national language at international journals. While economic strenght of a country was strongly correlated with number of international publications per 100.000 inhabitants, the correlation with international papers published in national languages was much less pronounced. There are two main reasons why the authors are not publishing in their native language at international medical journals. The first is obvious, number of international medical journals published in national language is small and decreasing from year to year; many coutries do not have any more international medical journals published in national language [9]. The second reason is also important, but less clear: the authors themselves may avoid publishing at journals printed in national language because they fear that their work will pass unnoticed by wider scientific community which does not understand this native language [10]. Both factors that lead to decrease or even extinguishing of medical publications of international importance in national languages could be ameliorated by appropriate actions of national governments: medical journals in national languages should be financially supported, and publications in national languages should be more valued by national universities for the purpose of academic promotion of the academic 
staff. Number of scientific publications is directly associated with economic strength of a country, for the obvious reason that any research needs some materials that bear certain costs [11]. However, extent of publishing in national language was also associated with wealth of a country, probably because there are more chances to have additional funds to support journals printed in national language [12]. Besides, countries with long tradition of scientific research in medicine, like France, Germany, Spain, Netherlands and Italy tend to keep and support national journals published in national languages. Main limitation of our study was its restriction to only one publication year; comparison of several years would give an insight in trends of publishing, both in English and in national languages. It would be much easier to understand causes of changes in publication practices if the trends were available.

\section{Conclusion}

Researchers from majority of European countries are publishing their studies predominantly or only in international medical journals printed in English language. Additional efforts should be made in the future to promote publishing in national languages, especially at medical journals of international significance.

\section{References}

[1] Ramírez-Castañeda V. Disadvantages in preparing and publishing scientific papers caused by the dominance of the English language in science: The case of Colombian researchers in biological sciences. PloS One. 2020; 15(9): e0238372.

[2] Rezaeian M. Disadvantages of publishing biomedical research articles in English for non-native speakers of English. Epidemiol Health. 2015; 37: e2015021.

[3] Di Bitetti MS, Ferreras JA. Publish (in English) or perish: The effect on citation rate of using languages other than English in scientific publications. Ambio. 2017 Feb; 46(1): 121-7.

[4] Picardi N. Rules to be adopted for publishing a scientific paper. Ann Ital Chir. 2016; 87: 1-3.

[5] Pérez Arbej JA, Cameo Rico MI, Arnáiz Esteban F, Martínez Pérez E, et al. [Impact of Spanish-language urological publications in periodicals in the English language]. Arch Esp Urol. 1997 Jun; 50(5): 427-32.

[6] Walvoort HC. [Medical science in the Dutch language]. Ned Tijdschr Geneeskd. 1997 Jan 4; 141(1): 57.

[7] PubMed [Internet]. PubMed. [cited 2021 Jan 5]. Available from: https://pubmed.ncbi.nlm.nih.gov/

[8] Countries | Data [Internet]. [cited 2021 Jan 5]. Available from: https://data.worldbank.org/country

[9] Jankovic SM, Masic I. Methodological Errors in Clinical Studies Published by Medical Journals of ExYugoslav Countries. Acta Inform Med 2020;28(2):84-93. doi: 10.5455/aim.2020.28.84-93.

[10] Olivier C, Casseyre P, Vayssairat M. [French medical periodicals in the international scene?]. Bull Acad Natl Med. 1989 Feb; 173(2): 141-4; discussion 144-147.

[11] Brown T, Gutman SA, Ho Y-S, Fong KNK. A bibliometric analysis of occupational therapy publications. Scand J Occup Ther. 2018 Jan; 25(1): 1-14.

[12] Tang CT, Wilkerson PM, Soon Y. Is research related to a country's economic development? An analysis of biomedical publications from several GCC and ASEAN countries from 1994-2013. Med J Malaysia. 2016 Apr; 71(2): 57-61. 